\title{
FABRICATION AND ANALYSIS OF VORTEX TUBE SETUP
}

\author{
Chaitanya M. Joshi ${ }^{1}$, Shivraj K. Jadhav ${ }^{2}$, Pravin D. Patil ${ }^{3}$ and Himani B. Kadam ${ }^{4}$
}

\begin{abstract}
Vortex tube is a device that separates compressed air into two streams simultaneously, one current of air hotter than the inlet temperature and one cooler, made even more remarkable by the absence of moving parts.

A vortex tube is designed and fabricated and several parameters (like length of pipe, orifice diameter, length of nozzle, selection of material for pipe and nozzle i.e. plastic pipe and brass for nozzle, acrylic for orifice and again plastic for reducers and collar.) are studied for the performance of the vortex tube. In a vortex tube, the incoming air is separated into two streams, one stream rejects energy and hence become colder than the incoming air while the other receives the rejected energy and thus has its temperatures elevated.

The size of the device can be miniature as pencil. The device has no moving parts which again reduces maintenance of the system. Also, from experiments instant cool and instant hot air from the outlets can be observed.
\end{abstract}

Keywords - Vortex Tube, Coefficient of performance, Cold air, Temperature separation effect, Kinetic Energy, Exergy.

\section{INTRODUCTION}

The Vortex tube is a mechanical device operating as a refrigerating or cooling machine without any moving parts, by separating a compressed air/gas stream into a low temperature region and a high temperature region. Such a separation of the flow into regions of low and high temperature is referred to as the temperature (or energy) separation effect. Generally, the vortex tube can be classified into two types. One is the counter-flow type (often referred to as standard type) and another is parallel or uni-flow type. The counter flow type consists of tube opened at both ends in which air (or in general the working gas) is introduced at a high pressure tangentially. A strongly swirling flow results in and the air/gas proceeds along the tube. The outer region of whirl is found to be warmer than the inner small whirl region experiences cooling (See Figure 1). An orifice positioned just behind the inlet of flow, separates the cool central air/gas which when exits on the left side of tube produces cooling effect. The fundamental aspects of the parallel flow vortex tube are the same as for the counter flow tube.

${ }^{1}$ Department of Mechanical Engineering TSSM's PVPIT Bavdhan, Pune, Maharashtra, India.

${ }^{2}$ Department of Mechanical Engineering TSSM's PVPIT Bavdhan, Pune, Maharashtra, India.

${ }^{3}$ Department of Mechanical Engineering TSSM's PVPIT Bavdhan, Pune, Maharashtra, India.

${ }^{4}$ Department of Mechanical Engineering TSSM's PVPIT Bavdhan, Pune, Maharashtra, India. 


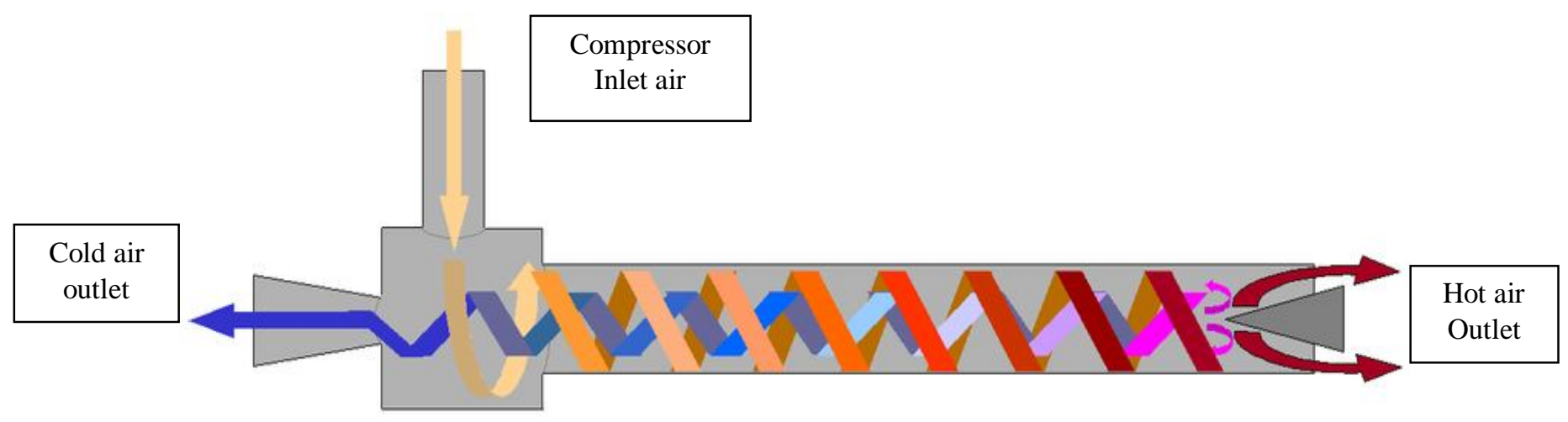

Figure 1: Basic working principle of a vortex tube

The various advantages of vortex tube are cooling with no moving parts, small, lightweight, low cost, maintenance free, able to produce instant cold air, cleanliness, convenience of operation and free from pollution due to non-CFC (Chlorofluorocarbon) exhaust, etc. Nowadays the property of vortex tube has a great variety of application in many industries. It has been widely used in the cooling industrial fields especially drilling, turning and welding. They are also used especially for cooling electronic controls, cooling machining operations, cooling CCTV cameras, setting hot melts, cooling soldered parts, cooling casting samples, cooling electronic component, cooling heat seals, etc.

\section{EXPERIMENTAL SETUP}

Counter flow vortex tube is used to study the vortex tube phenomenon. The main bush contains the orifice plate and the nozzle bush. The main tube and the cold pipe are threaded lo the main bush at its either ends, the conical valve is placed at open end of the main tube. As shown in the figure 2, the thermocouple TH and TC are placed near the conical valve and orifice plate to measure the hot and the cold temperature of the air leaving the vortex tube. Air from the compressor is fed to main tube through nozzle. The pressure of air entering is varied to analyze its effect on the performance of the vortex tube. The air gets tangential entry in the tube. As it expands it gets swirl. Air travel towards the valve side end. The valve is having conical shape hence it can be adjusted to control the mass flow rate of the air, Because of the partial opening of the valve some of the air escapes out and remaining is reflected back towards the nozzle through the core of the tube.

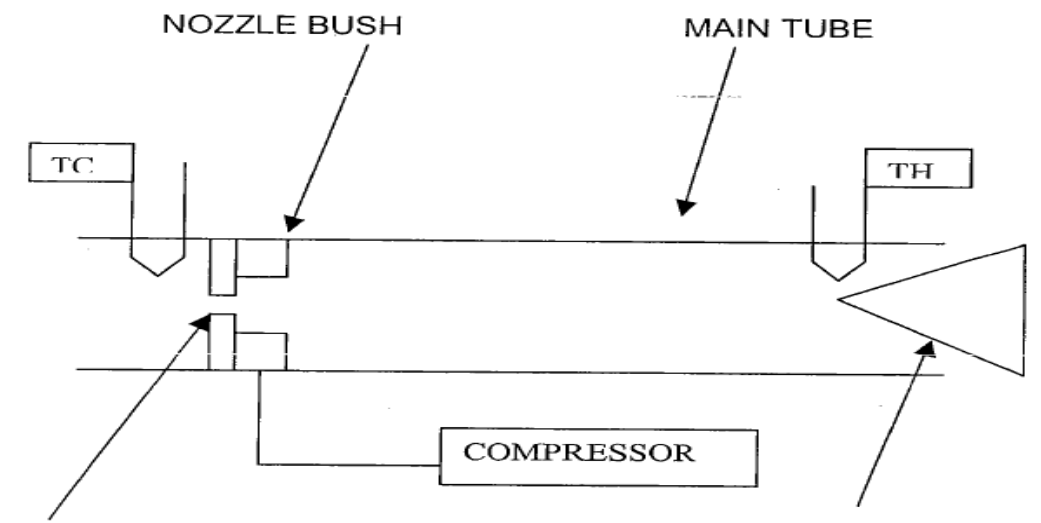

ORIFICE

CONICAL VALVE

Fig 2: Sketch of experimental setup 
The geometrical data of the vortex tube is as follows,

Inner diameter of the main tube (D)

Length of the tube (L)

Orifice hole diameters (d)

Orifice thickness $(\mathrm{t})$

Nozzle diameter $\left(d_{n}\right)$

Collar diameter $\left(\mathrm{d}_{\mathrm{c}}\right)$

Collar length (1)

Reducer diameter small end

Reducer diameter large end

$$
\begin{aligned}
& =12.70 \mathrm{~mm} \\
& =1250 \mathrm{~mm} \\
& =2.00 \mathrm{~mm}, 3.00 \mathrm{~mm}, 4.00 \mathrm{~mm} \\
& =12.00 \mathrm{~mm} \\
& =10.00 \mathrm{~mm} \\
& =43.0 \mathrm{~mm} \\
& =60.00 \mathrm{~mm} \\
& =12.70 \mathrm{~mm} \\
& =42.50 \mathrm{~mm}
\end{aligned}
$$

The material used for pipe, socket, and reducer is U-PVC. For nozzle brass and for orifice acrylic is used. The orifice diameters are chosen with constant increments and it is ensured that the ratio of orifice diameter to tube diameter should be within 0.20 to 0.55 . Certain modifications have been made in the design. The spiral chamber, as shown in figure 2, is modified due to fabrication constraint. The modified spiral chamber consists of a ring. A tangential hole of required diameter drilled through it. The hole is made tangential to the inner circle of the ring.

\section{EXPERIMENTAL FORMULAE AND RESULT}

- Temperature difference :

This can be obtained by simple formula as

$$
T=T_{h}-T_{c}
$$

Where,

$\mathrm{T}_{\mathrm{h}}$ - Hot side air temperature in Kelvin.

$\mathrm{T}_{\mathrm{c}}$ - Cold side air temperature in Kelvin

- Cold mass fraction:

It is the ratio of mass of air leaving the tube as cold air to the mass of air entering the tube. It is denoted by $\boldsymbol{\mu}$ and is given by formula,

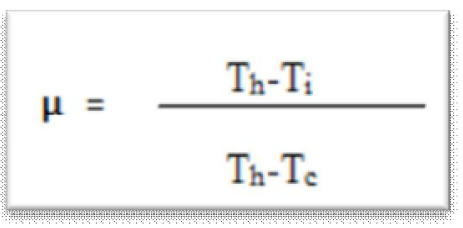

Where,

Ti- Inlet air temperature in Kelvin.

$\mathrm{T}_{\mathrm{h}}$ - Hot side air temperature in Kelvin.

$\mathrm{T}_{\mathrm{c}}$ - Cold side air temperature in Kelvin.

- $\quad$ Refrigerating effect:

The cooling effect produced by the cold air leaving the tube is known as exergy and it is defined as, 
Exergy is a energy available within the boundary limit and is given as,

$R E=m * C_{p} *\left(T_{i} T_{c}\right)$

Where,

m- Mass of air in $\mathrm{kg}$.

$\mathrm{C}_{\mathrm{p}}$ - Specific heat of air in $\mathrm{j} / \mathrm{kg}-\mathrm{K}$

$\mathrm{T}_{\mathrm{i}^{-}}$Inlet air temperature in Kelvin.

$\mathrm{T}_{\mathrm{c}^{-}}$Cold air temperature in Kelvin.

$\mathrm{RE}=$ Refrigerating Effect

For the calculation purpose the mass of cold is taken as $1 \mathrm{~kg}$.

- Coefficient Of Performance ( COP )

This can be obtained as

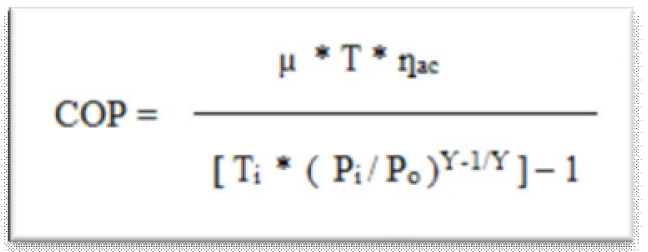

Where,

$\boldsymbol{\mu}$ - Cold mass fraction

T- Temperature difference in Kelvin

$\mathrm{P}_{\mathrm{o}^{-}}$Outlet Pressure in bars

$\mathrm{P}_{\mathrm{i}}$ - Inlet pressure in bars

$\square_{\mathrm{ac}}=$ adiabatic efficiency of the compressor

Y-gamma (constant, 1.4)

\begin{tabular}{|c|c|c|c|c|c|}
\hline Orifice diameter & $\begin{array}{c}\text { Pressure } \\
(\mathrm{bar})\end{array}$ & $\begin{array}{c}\mathrm{T}=\mathrm{T}_{\mathrm{h}}-\mathrm{T}_{\mathrm{c}} \\
\left({ }^{\circ} \mathrm{C}\right)\end{array}$ & $\mu$ & $\begin{array}{c}\mathrm{RE} \\
(\mathrm{KJ} / \mathrm{Kg})\end{array}$ & COP \\
\hline 2 & 5 & 16.6 & 0.0723 & 15.477 & 0.0201 \\
\hline 3 & 2 & 4.7 & 0.0851 & 4.32 & 0.0102 \\
\hline 4 & 2 & 4.4 & 0.1364 & 3.81 & 0.013 \\
\hline
\end{tabular}

These are some of the results obtained when actual test was taken on setup.

$\underline{\text { Sample calculations are for orifice diameter } 2 \mathrm{~mm} \text {, at } 5 \text { bar pressure when inlet temp was } 30^{\circ} \mathrm{C}}$

\section{Given}

$$
\mathrm{T}_{\mathrm{h}}=31.2{ }^{\circ} \mathrm{C} \quad \mathrm{T}_{\mathrm{c}}=14.6^{\circ} \mathrm{C} \quad \mathrm{T}_{\mathrm{i}}=30 \quad \mathrm{P}=5 \mathrm{bar}
$$

\section{Solution}

1) Temperature Difference :

$$
\begin{aligned}
& \mathrm{T}=\mathrm{T}_{\mathrm{h}}-\mathrm{T}_{\mathrm{c}} \\
& =31.2-14.6
\end{aligned}
$$




\section{$\mathrm{T}=16.6{ }^{\circ} \mathrm{C}$}

2) Cold Mass Fraction :

$$
\begin{aligned}
& \boldsymbol{\mu}=\frac{\mathrm{T}_{\mathrm{h}}-\mathrm{T}_{\mathrm{i}}}{\mathrm{T}_{\mathrm{h}}-\mathrm{T}_{\mathrm{c}}} \\
& \boldsymbol{\mu}=(31.2-30) /(31.2-14.6) \\
& \boldsymbol{\mu}=\mathbf{0 . 0 7 2 3}
\end{aligned}
$$

3) Refrigerating effect: Exergy

$$
\begin{aligned}
\mathrm{RE} & =\mathrm{m} * \mathrm{C}_{\mathrm{p}} *\left(\mathrm{Ti}-\mathrm{T}_{\mathrm{c}}\right) \\
& =1 * 1.005 *(30-14.6)
\end{aligned}
$$

\section{$\mathrm{RE}=15.477 \mathrm{KJ} / \mathrm{Kg}$}

3) Coefficient Of Performance :

$$
\begin{aligned}
\mathrm{COP} & =\frac{\mu * \mathrm{~T}^{*} \mathrm{\eta}_{\mathrm{ac}}}{\left[\mathrm{T}_{\mathrm{i}} *\left(\mathrm{P}_{\mathrm{i}} / \mathrm{P}_{\mathrm{o}}\right)^{\mathrm{Y}-1 / \mathrm{Y}}\right]-1} \\
& =\frac{0.0723 * 16.6 * 0.78}{\left[30 *\left(\frac{5}{1.033}\right)^{\wedge} 1.4-1 / 1.4\right]-1}
\end{aligned}
$$

$\mathrm{COP}=\mathbf{0 . 0 2 0 3}$

\section{III.I FLOW ANALYSIS}

Boundary conditions selected for each analysis were,

- Mass flow rate of air $(\mathrm{m})-1 \mathrm{~kg} / \mathrm{s}$, constant.

- Inlet air pressure $\left(\mathrm{p}_{\mathrm{i}}\right)-2$ bars, constant.

- Inlet air temperature $\left(\mathrm{T}_{\mathrm{i}}\right)-300 \mathrm{~K}$

- Density- $1.225 \mathrm{~kg} / \mathrm{m} 3$, constant

- Specific Heat $\left(\mathrm{C}_{\mathrm{p}}\right)-1006.43 \mathrm{j} / \mathrm{kg}-\mathrm{k}$, constant

For this analysis quadrilateral mesh with mesh size 2 for main components like pipe, nozzle, collar, reducer is used and for the small part of orifice triangular mesh with mesh size 1.2 is used. Selection of mesh size was made 
according quality of mesh produced using various mesh size; we chose optimum size taking into consideration size of actual part.

The conclusion found out from bellows analysis is that sudden expansion near the cold end is consider as the main reason for the temperature drop, since there is no energy transferred outwards from the central region. Kinetic energy is transferred outwards from the rotational vortex in the central region and contributes to the temperature rise in the periphery near the hot end.

\section{FLUENT ANALYSIS RESULTS}

For orifice of $2 \mathrm{~mm}$ diameter temperature change ranges between hot and cold side is found out to be $307 \mathrm{~K}$ to $290 \mathrm{~K}$. For orifice of $4 \mathrm{~mm}$ diameter temperature change ranges between hot and cold side is found out to be $304 \mathrm{~K}$ to $285 \mathrm{~K}$.

Analysis on orifice with $2 \mathrm{~mm}$ diameter with inlet air temperature of $300 \mathrm{~K}$ and $2 \mathrm{bar}$ pressure.
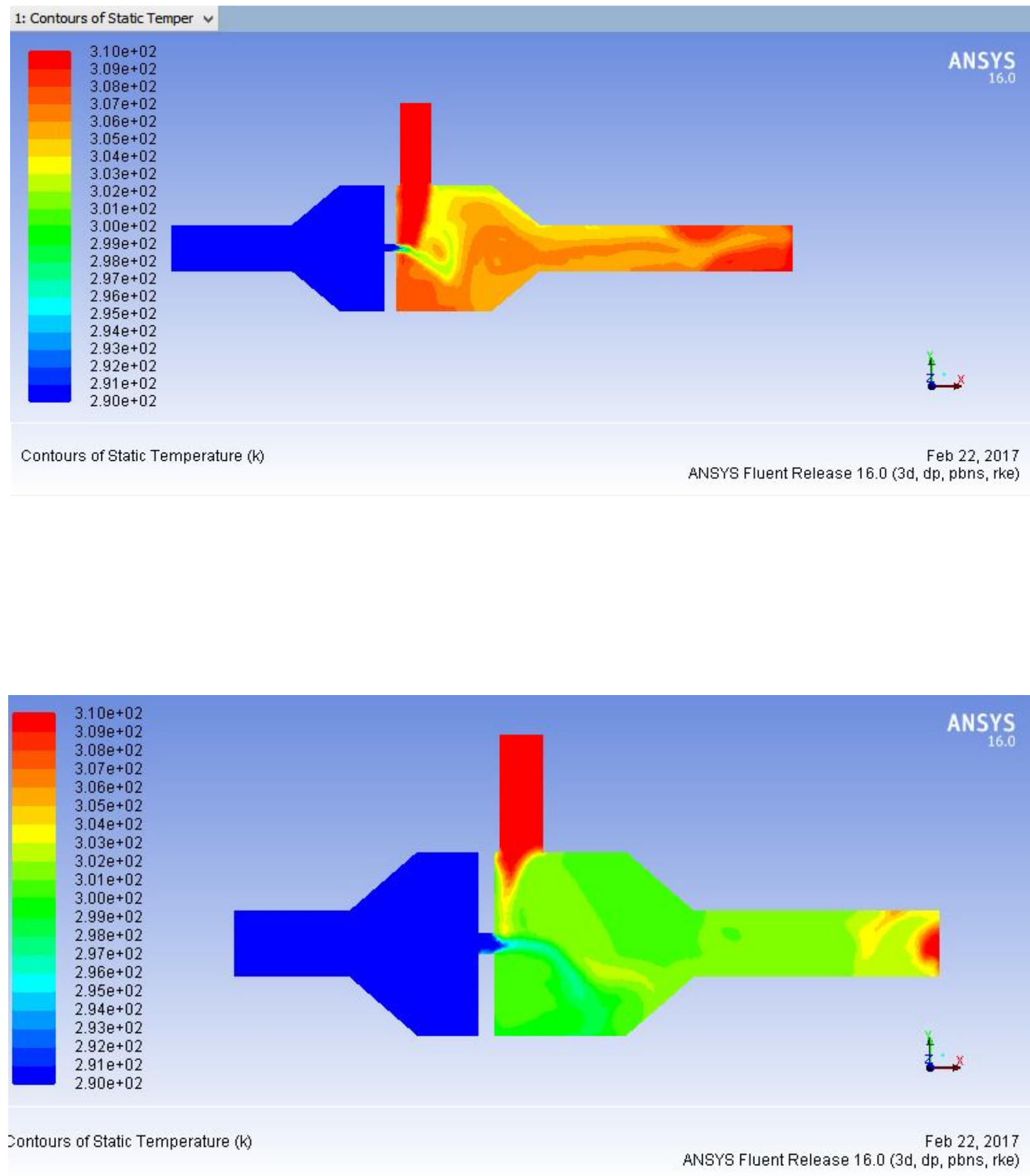
Analysis on orifice with 4mm diameter with inlet air temperature of $300 \mathrm{~K}$ and 3 bar pressure.

\section{IV.CONCLUSION}

Although several explanations for the temperature separation vortex tube have been proposed, due to the complexity of the internal flow, there has not been a well accepted explanation and the physical process inside the vortex tube remains unclear. This ongoing research focuses on the temperature change of flow inside a vortex tube aiming to locate the dominant reason for the temperature separation in a vortex tube.

This experimental study presents detailed study of the temperature change inside a counter-flow vortex tube. It is noted that in the central region of the tube, the rotational vortex at the hot end was transformed to a forced vortex near the injection and kinetic energy is only transferred outwards from the hot end to the cold end.

Using the detailed flow properties (density, mass flow rate, pressure, temperature.), the exergy inside the vortex tube is calculated and provides positive support for the proposed results of analysis. Sudden expansion near the cold end is consider as the main reason for the temperature drop, since there is no energy transferred outwards from the central region. The slightly changed exergy near the hot end indicates that the temperature rise is mainly due to the stagnation of the structure of multi-circulation. Kinetic energy is transferred outwards from the rotational vortex in the central region and contributes to the temperature rise in the periphery near the hot end.

\section{REFERENCES}

[1]. Pong jet Promvonge and Smith Eiamsa-ard (2005) "Investigation on the Vortex Thermal Separation in a Vortex Tube Refrigerator". Aresearch article on Science Asia 31 December,doi: 10.2306/science asial 513- 1874.2005.31.215

[2]. Gupta U. S, Joshi M. K. and Pawar C.B on Experimental Performance and evaluation of counter flow vortex tube, ShriVaishnav Institute of Technology and Science(SVITS), Indore(INDIA), Vol. 7 No. 1A, July-September 2012[1-2]

[3]. Guillaume DW and Jolly III JL (2001) Demonstrating the achievement of the lower temperatures with two-stage vortex tubes. Review of Scientific Instruments 72 (8), 3446-48.

[4]. Pinar A. M., Uluer O., Kirmaci V., "Optimization of counter flow Ranque-Hilsch vortex tube performance using Taguchi method." International journal of refrigeration, Vol.32, (2009), pg no. 1487-1494.

[5]. Piralishvili S. A. And Fuzeeva A. A., "Similarity of the Energy-Separation Process in Vortex Ranque Tubes." Journal of Engineering Physics and Thermophysics, Vol. 79, No.1, (2006).

[6]. Eiamsa-ard S., Promvonge P., "Numerical prediction of vortex flow and thermal separation in a subsonic vortex tube." Journal of Zhejiang University SCIENCE A, Vol. 7(8), (2006), pg no.1406-1415.

[7]. Baghdad M., Ouadha A., Imine O., Addad Y., "Numerical study of energy separation in a vortex tube with different RANS models." International Journal of Thermal Sciences, Vol. 50, (2011), pg no. 2377-2385.

[8]. Hilsch R (1947) the Use of Expansion of Gases in a Centrifugal Field as a Cooling Process. Review of Scientific Instruments 18 (2), 108 - 13.

[9]. Ranque G. Method and apparatus for obtaining from a fluid under pressure two outputs of fluid at different temperatures. US1934.

[10]. Scheper GW (1951) The Vortex Tube; Internal Flow Data and a Heat Transfer Theory .Journal of the ASRE, Refrigerating Engineering 59, 985 - 89. 